\title{
Prevalence of mutation and phenotypic expression associated with sulfadoxine-pyrimethamine resistance in Plasmodium falciparum and Plasmodium vivax
}

\author{
Haytham A. Zakai ${ }^{1}$, Wajihullah Khan ${ }^{1}$ and Umme Asma ${ }^{2}$ \\ ${ }^{1}$ Faculty of Applied Medical Sciences, King Abdulaziz University, Jeddah, Kingdom of Saudi Arabia; \\ ${ }^{2}$ Department of Zoology, Faculty of Life Sciences, Aligarh Muslim University, Aligarh, Uttar Pradesh, India
}

\begin{abstract}
Therapeutic efficacy of sulfadoxine-pyrimethamine (SP), which is commonly used to treat falciparum malaria, was assessed in isolates of Plasmodium falciparum (Welch, 1897) and Plasmodium vivax (Grassi et Feletti, 1890) of Aligarh, Uttar Pradesh, North India and Taif, Saudi Arabia during 2011-2012. Both the species showed mutations in dihydrofolate reductase (DHFR) enzyme as they have common biochemical drug targets. Mutation rate for pfdhfr was higher compared to pvdhfr because the drug was mainly given to treat falciparum malaria. Since both the species coexist, $P$. vivax was also exposed to SP due to faulty species diagnosis or medication without specific diagnosis. Low level of mutations against SP in P. falciparum of Saudi isolates indicates that the SP combination is still effective for the treatment of falciparum malaria. Since SP is used as first-line of treatment because of high level of resistance against chloroquine (CQ), it may result in spread of higher level of mutations resulting in drug resistance and treatment failure in near future. Therefore, to avoid further higher mutations in the parasite, use of better treatment regimens such as artesunate combination therapy must be introduced against SP combination.
\end{abstract}

Keywords: molecular study, malaria, drug resistance, India, Saudi Arabia

Malaria is the most prevalent parasitic disease worldwide, responsible for an estimated 225 million clinical cases each year. It mainly affects children, pregnant women and non-immune adults who frequently die as victims of cerebral manifestations and anaemia (Quintero et al. 2011). It is major cause of death in tropical and sub-tropical countries where it claims approximately 655 thousand lives each year (World Health Organization 2010). This disease is managed by anti-malarial drugs as no effective vaccine is yet available. However, the parasite has developed resistance against most commonly used antimalarial chloroquine $(\mathrm{CQ})$, posing a major problem for malaria control programme (Mitra et al. 2006).

In case of doubtful species diagnosis, sulfadoxinepyrimethamine (SP) combination is usually prescribed by clinicians to avoid any risk on the life of patient and, thereby, increases SP pressure on parasite population. With the spread of chloroquine resistant malaria in different countries including India and Saudi Arabia, SP alone or in combination with artesunate is used as an alternate drug. This drug combination targets the folate biosynthetic pathway of Plasmodium species; blocking the nucleic acid biosynthesis and thus causing parasite death (Peterson et al. 1988, Triglia et al. 1997). Pyrimethamine acts on the dihydrofolate reductase enzyme of Plasmodium falciparum (Welch, 1897) (PFDHFR) and inhibits the folate biosynthesis pathway of the parasite (Gregon and Plowe 2005). Point mutation in PFDHFR reduces its capacity to bind with the drug, resulting in the emergence of resistant parasite strains (Mbugi et al. 2006, Gesase et al. 2009). There are mutations at more than three loci in the parasite enzyme in endemic countries (Peterson et al. 1988, Sirawaraporn et al. 1997).

Pyrimethamine resistance develops in a progressive manner and treatment failure occurs. Since both $P$. falciparum and P. vivax (Grassi et Feletti, 1890) contain the same target enzymes, the antifolate drug also affects P. vivax - see Imwong et al. (2003), Hastings et al. (2004), de Pecoulas et al. (2004), Kaur et al. (2006), Barnadas et al. (2008). Keeping these facts in mind, study on the prevalence of mutations and phenotypic expressions associated with sulfadoxine-pyrimethamine resistance in $P$. falciparum and $P$. vivax is attempted in the samples obtained from India and Saudi Arabia.

\section{MATERIALS AND METHODS}

Blood samples collected from the patients with fever who attended the Medical College and other malaria clinics of Aligarh, India during 2011-2012, and the Communicable Diseases Control Centre, Taif, Saudi Arabia, from the patients who visited Jazan and Yemen earlier, were included in this study. Thick and thin blood smears of these patients were screened by E-600

Address for correspondence: W. Khan, Faculty of Applied Medical Sciences, King Abdulaziz University, P.O. Box 80216, Jeddah 21589, Kingdom of Saudi Arabia. Phone: +966 538254634; E-mails: wajihullahkhan@yahoo.co.in; wajihullahkhankau@gmail.com 
research microscope at $100 \times$. These patients were treated according to National Drug Policies of the respective countries. Prepared slides from Taif region as well as Aligarh, India were observed for phenotypic variations in Plasmodium falciparum. PFDHFR and PVDHFR gene mutation studies were also conducted using the above blood samples.

DNA extraction, PCR amplification and nucleotide sequencing of DHFR gene:

DNA extraction, amplification and nucleotide sequencing were done as described earlier by Alam et al. (2007). DNA was extracted from the blood of patients that were infected with P. falciparum and P. vivax using Accu Prep Genomic DNA extraction kit (Bioneer Corporation of Korea). The DNA was eluted in Tris EDTA buffer ( $\mathrm{pH} \mathrm{8.0)}$ and an aliquote was used for PCR amplification. A fragment of $1014 \mathrm{bp}$ of $P$. vivax dhfr-ts gene was amplified using primers PvDA (5'-ACCGCACCAGTTGATTCCTAC-3') (forward) and PvDB (5'-ACCGCACCAGTTGATTCCTAC-3') (reverse). The cycling parameters were a 10 min initial denaturation at $94^{\circ} \mathrm{C}$ followed by $35 \mathrm{cy}$ cles with a $30 \mathrm{sec}$ denaturation at $94^{\circ} \mathrm{C}$, one minute annealing at $58^{\circ} \mathrm{C}$, one minute extension at $72^{\circ} \mathrm{C}$ and a final 10 min extension at $72^{\circ} \mathrm{C}$. After diluting 10 times, this priming PCR product, was used as a DNA template for nesting PCR to amplify the 784-bp region, which covered the entire DHFR domain.

Primers PvDF (5'-ATGGAGGACCTTTCAGATGT-3') (forward) and PvDR (5'-AACGCATTGCAGTTCTCCGA-3') (reverse) were used for nested PCR with a 10 minutes initial denaturation at $94^{\circ} \mathrm{C}$ followed by 35 cycles with a $30 \mathrm{sec}$ annealing at $54^{\circ} \mathrm{C}$ and a one minute extension at $72^{\circ} \mathrm{C}$ as the cycling parameters. Primers PvDA (covering -75 to -55 bp upstream to the Pvdhfr-ts start codon), PvDB, PvDF and PvDR were designed from the known Pvdhfr-ts sequence of pyrimethamine-sensitive P. vivax isolate ARI/Pakistan (98123). DNA was extracted and subjected to PCR amplification of a 720-bp fragment to the pfdhfr gene using the method described by Ahmad et al. (2004). An aliquot of the primary amplicon was diluted and subjected to seminested PCR using primer AMP1 (Plowe et al. 1997) and DHFRR2 (5'-ACAGAAATAATTTGATACTCA-3'). Only 30 cycles were carried out for seminested PCR under the same conditions as has been used for primary PCR. The PCR products were purified and subjected to sequencing according to Mitra et al. (2006), using an ABI Big dye terminator Ready Reaction Kit (version 3.1), and the ABI Prism 310 genetic analyser (PE Applied Biosystems, Foster City, California, USA).

Individual bands of each PCR product were excised from the agrose gel and purified using an Accu Prep gel purification kit (Bioneer Corporation, Korea) according to manufacturer's instructions. The entire pvdhfr gene was sequenced using primer PvDM (5'-GTTAGCGTCTTGTCTTGGAAAGCAC-3') and PvDR, whereas primers for pfdhfr gene sequencing were same as described by Jalah et al. (2005). The nucleotide sequences were translated into amino acids using the edit sequence program (Lasergene 1999, version 5.1, DNASTAR Inc., Madison, WI, USA). The amino acid sequences were aligned using gen Doc Multiple Sequence Alignment Editor and Shading Utility (Version 2.6.002)

\section{Statistical analysis:}

The chi-square test was applied to assess the trends of DHFR mutations in $P$. falciparum and $P$. vivax infections. $\mathrm{P}$ value of $<0.05$ was considered significant.

\section{RESULTS}

Sequencing of pfdhfr and pvdhfr gene showed mutations in both Indian and Saudi isolates. Among Indian isolates, the pfdhfr mutations were observed at codons S108N, C59R and N51I. Maximum number of isolates $(92 \%)$ showed mutations at codon $108(\mathrm{~S} 108 \mathrm{~N})(\mathrm{P}<0.05)$ followed by mutations at codon 59 (C59R, 55\%) and least of $4 \%$ at codon 51 (N51I). Majority of the Indian isolates were found to contain double pfdhfr mutations (Figs. 1, 2; Table 1-3). The double mutation C59R plus S108N was much more common and observed in 28 isolates $(55 \%$; $\mathrm{n}=51$ ) with genotype $\mathrm{A}_{16}, \mathrm{~N}_{51}, \mathrm{R}_{59}, \mathrm{~N}_{108}, \mathrm{I}_{164}$ than the N51I plus $\mathrm{S} 108 \mathrm{~N}$ mutations in two isolates $(4 \% ; \mathrm{n}=51)$ with genotype $\mathrm{A}_{16}, \mathrm{I}_{51}, \mathrm{C}_{59}, \mathrm{~N}_{108}, \mathrm{I}_{164}$. Single mutation at codon $108(\mathrm{~S} 108 \mathrm{~N})$ was detected in 17 isolates $(33 \%$; $\mathrm{n}=51)$ having genotypes $\mathrm{A}_{16}, \mathrm{~N}_{51}, \mathrm{C}_{59}, \mathrm{~N}_{108}, \mathrm{I}_{164}$. Only 4 isolates $(8 \% ; n=51)$ showed wild type amino acids with genotype $\mathrm{A}_{16}, \mathrm{~N}_{51}, \mathrm{C}_{59}, \mathrm{~S}_{108}, \mathrm{I}_{164}$. Out of 14 isolates of Plasmodium falciparum from Saudi Arabia, only two $(14 \%$; $n=14)$

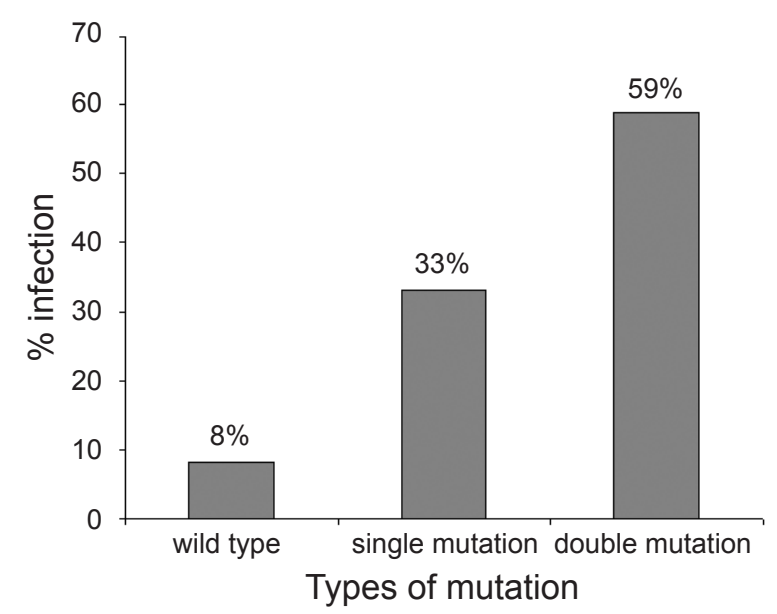

Fig. 1. Prevalence of wild type and single and double mutations in pfdhfr gene of Plasmodium falciparum in Aligarh, India.

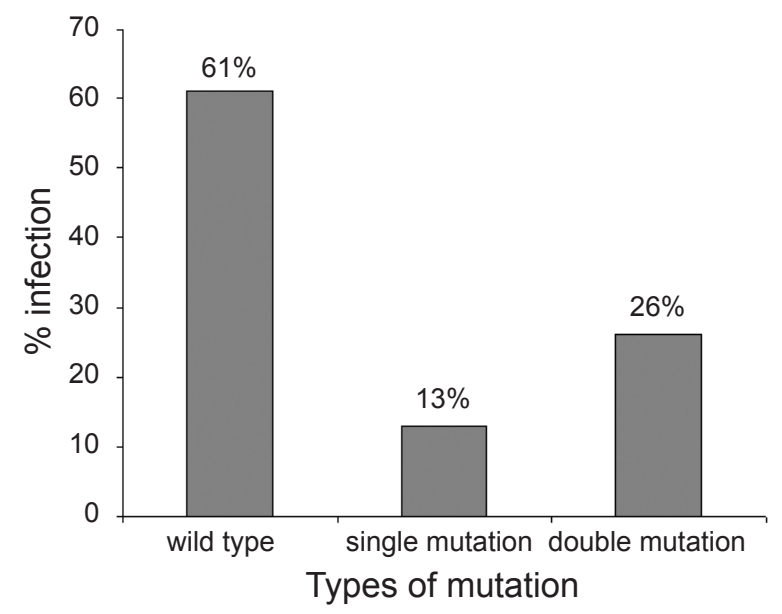

Fig. 2. Prevalence of wild type and single and double mutations in pvdhfr gene of Plasmodium vivax in Aligarh, India. 
showed mutations at codon 59 (C59R) with genotype $\mathrm{A}_{16}$, $\mathrm{N}_{51}, \mathrm{R}_{59}, \mathrm{~S}_{108}, \mathrm{I}_{164}$. Remaining $12(86 \% ; \mathrm{n}=14)$ showed wild amino acids $\mathrm{A}_{16}, \mathrm{~N}_{51}, \mathrm{C}_{59}, \mathrm{~S}_{108}, \mathrm{I}_{164}$.

Mutation analysis by sequencing DHFR domain of the pvdhfr-ts from $46 P$. vivax isolates revealed that the mutations occurred at $\mathrm{S}_{117} \mathrm{~N}, \mathrm{~S}_{93} \mathrm{H}$ and $\mathrm{S}_{58} \mathrm{R}$ codons. Frequency of mutation among the isolates from Aligarh, Uttar Pradesh, north India was higher at codon $\mathrm{S}_{117} \mathrm{~N}$ followed by the codon $\mathrm{S}_{93} \mathrm{H}$. A total of 28 isolates $(61 \% ; \mathrm{n}=46)$ contained the wild type amino acids with genotype at codons $\mathrm{F}_{57}, \mathrm{~S}_{58}, \mathrm{~T}_{61}, \mathrm{~S}_{93}, \mathrm{~S}_{117}$. Among the remaining isolates, the frequency of double mutations of DHFR was highest and observed in 12 cases $(26 \% ; n=46)$ where genotype was $\mathrm{F}_{57}, \mathrm{R}_{58}, \mathrm{~T}_{61}, \mathrm{~S}_{93}, \mathrm{~N}_{117}$. Only six isolates $(13 \% ; \mathrm{n}=46)$ showed mutations at single codon $\mathrm{S} 93 \mathrm{H} / \mathrm{S} 117 \mathrm{~N}$ of $6.5 \%$ each and the genotypes were $\mathrm{F}_{57}, \mathrm{~S}_{58}, \mathrm{~T}_{61}, \mathrm{H}_{93}, \mathrm{~S}_{117}$ and $\mathrm{F}_{57}$, $\mathrm{S}_{58}, \mathrm{~T}_{61}, \mathrm{~S}_{93}, \mathrm{~N}_{117}$.

During the present study, it was observed that rings of $P$. falciparum, which otherwise varied in size and shape, showed little more prominent variations in terms of shape and thickness of the cytoplasm (data not shown). In $P$. falciparum having mutations at two codons, rings were much oblong with the thickened cytoplasm at one end. It remains unclear whether this change in size and shape of rings of $P$. falciparum is a mere coincidence or it is due to the alterations of the amino acid in DHFR enzyme.

\section{DISCUSSION}

Antifolate drugs are generally used for the treatment of falciparum malaria in developing countries. According to the National Drug Policy of both, India and Saudi Arabia, chloroquine-resistant uncomplicated falciparum malaria cases should be treated with sulfadoxine-pyrimethamine (SP). In regions where resistance due to chloroquine (CQ) has reached a very high level, SP is the first-line of antimalarial. There are few primary health care centres and medical colleges in India and Saudi Arabia where artesunate-based combined therapy has been introduced as an alternative treatment. Several countries have already abandoned chloroquine and SP monotherapy because of emergence and worsening rise of CQ and SP-resistance (Bosco et al. 1998, Shretta et al. 2000). If Plasmodium falciparum and $P$. vivax coexist in any region, both are at risk of being exposed to the antifolate drug (SP) as they have common target enzymes (Tjitra et al. 2002, Imwong et al. 2003, de Pecoulas et al. 2004, Gregon and Plowe 2005, Barnadas et al. 2008).

In the present study, a low level of SP resistance with a total of $59 \%$ pfdhfr mutations as C59R plus S108N and N51I plus S108N were recorded from Aligarh, Uttar Pradesh of North India where $P$. vivax dominates over $P$. falciparum. In contrast, higher levels of SP resistance and treatment failures were recorded from Kenya, Tanzania, northeastern part of India, Ethiopia and the Sudan, where intense malaria transmission was observed and
Table 1. DHFR genotypes of Plasmodium falciparum in Aligarh, Uttar Pradesh, India.

\begin{tabular}{lll}
\hline Genotype & Number of mutations Number of isolates \\
\hline A16 N51 C59 S108 I164 & 0 & $4(8 \%)$ \\
A16 N51 C59 N108 I164 & 1 & $17(33 \%)$ \\
A16 N51 R59 N108 I164 & 2 & $18(55 \%)$ \\
A16 I51 C59 N108 I164 & 2 & $2(4 \%)$ \\
\hline & & Total No. $=51$ \\
\hline
\end{tabular}

Table 2. DHFR genotypes of Plasmodium vivax in Aligarh, Uttar Pradesh, India.

\begin{tabular}{lll}
\hline Genotype & \multicolumn{2}{l}{ Number of mutations Number of isolates } \\
\hline F57 S58 T61 S93 S117 & 0 & $28(61 \%)$ \\
F57 S58 T61 S93 N117 & 0 & $3(6.5 \%)$ \\
F57 S58 T61 H93 S117 & 1 & $3(6.5 \%)$ \\
F57 R58 T61 S93 N117 & 2 & $12(26 \%)$ \\
\hline & & Total No. $=46$ \\
\hline
\end{tabular}

Table 3. DHFR genotypes of Plasmodium falciparum in Taif region, Saudi Arabia.

\begin{tabular}{lll}
\hline Genotype & \multicolumn{2}{l}{ Number of mutations Number of isolates } \\
\hline A16 N51 C59 S108 I164 & 0 & $12(86 \%)$ \\
A16 N51 R59 S108 I164 & 1 & $2(14 \%)$ \\
\hline & & Total No. $=14$ \\
\hline
\end{tabular}

$P$. falciparum species dominates over $P$. vivax (Pearce et al. 2003, Ahmad et al. 2006, Schunk et al. 2006).

It seems that there is an association between the degree of malaria transmission and number of pfdhfr mutations. Mutations in pfdhfr gene have been used as an indicator to predict treatment failure to SP in many areas where malaria is endemic. However, patient's response to the treatment is significantly dependent on factors such as host immunity profile of treated patients (Happi et al. 2005). However, in endemic countries where higher doses of SP are given, mutations in pfdhfr gene are increasing rapidly and resulting in treatment failures. Rapid spread of SP resistant strain has threatened its use and, therefore, better treatment regimen are being sought to replace SP (Takechi 2001).

In Taif region of Saudi Arabia, a low level of SP resistance is observed only at codon 59 of pfdhfr enzyme (C59R) in 14\% isolates. This is in agreement with the earlier report from Saudi Arabia (Al-Harthi 2007) in which $10.5 \%$ cases from Jazan showed mutation at the same codon (C59R). Similarly low level resistance was also reported from neighbouring border country Yemen where use of SP is still effective (Abdulgodos et al. 2009, Mubjer et al. 2011). The prevalence of mutations at codon 59 (C59R) in Saudi Arabia and Yemen, where SP was used as second-line treatment for a relatively short period, is lower. Studies with molecular markers have confirmed rapid development of resistance after the drug was used 
at national level in a number of settings. (Sridaran et al. 2010, Zakeri et al. 2010).

We observed low level of mutations in pvdhfr gene in Aligarh, Uttar Pradesh, which is located in northern India, having wild type of amino acids in majority of the cases $(61 \% ; n=46)$. Double and single mutations were observed in $12(26 \% ; n=46)$ and six isolates $(13 \% ; n=46)$, respectively. These figures are almost half of pfdhfr in the same region, which might be due to the simple reason that $P$. falciparum was actually treated with SP. Since $P$. vivax is the most prevalent species in the study area and have mixed infections too, dhfr of this species showed mutations against SP as it has the same drug target and was exposed to this drug because of wrong diagnosis and/or medications without species diagnosis.

Unfortunately, resistance developed relatively quickly when SP was widely used in endemic countries. Epidemiological and molecular studies on P. falciparum and $P$. vivax very clearly indicate that the dhfr enzyme is the therapeutic target of SP (Nzila et al. 2000, Tjitra et al. 2002, Imwong et al. 2003, de Pecoula et al. 2004, Hastings 2004). As a result, resistance to the SP is determined by specific point mutations in the parasite dhfr gene. These mutations cause alterations of key amino acid residues in the active sites of these enzymes reducing the affinity of enzymes for the drug (Foote and Cowman 1994).

Plasmodium vivax infections are not often treated with SP but this species got exposed to SP because of mixed infection and caused mutations (Kaur et al. 2006, Khatoon et al. 2009, Zakeri et al. 2010). The continuous use of SP as first-line antimalarial drug in endemic areas, where both $P$. vivax and $P$. falciparum species coexist, may increase the risk of mutations in the dhfr gene leading to a higher level of resistance against this combination in the near future. Therefore, continuous surveillance of $P$. vivax and P. falciparum molecular markers are needed to monitor the development of resistance to SP in endemic foci in poor countries, where this drug is used quite extensively due to its cost-effectiveness and easy availability, and taken as a single dose.

In conclusion, both $P$. falciparum and $P$. vivax showed mutations in DHFR enzyme against SP. In India, mutation rate for pfdhfr against SP was higher compared to pvdhfr. Low level of mutation in pfdhfr against this drug in Saudi Arabia indicates that SP is still effective for treatment of falciparum malaria, but its use as first-line of treatment may result in higher level of mutations resulting in drug resistance and treatment failures in near future. Therefore, to avoid further higher mutations in dhfr enzyme of Plasmodium, use of better treatment regimens such as artesunate combination therapy must be introduced against SP combination.

Acknowledgements. This study was funded by The Deanship of Scientific Research (DSR), King Abdulaziz University, Jeddah (grant No. 1-142-D1432), which is also acknowledged for technical support. The authors also wish to thank Dr. Shabi Fatma Abidi for critical review and help in preparation of this manuscript.

\section{REFERENCES}

Abdulgodos M.A., Al-Shamahy H.A., Al-Harazy A.H., Harmal N.S. 2009: Therapeutic efficacy of sulfadoxine/pyrimethamine against Plasmodium falciparum in Yemen. Med. Principl. Pract. 18: 62-66.

Ahmad A., Bararia D., Vinayak S., Yameen M., Biswas S., Dev V., Kumar A., Ansari M.A., Sharma Y.D. 2004: Plasmodium falciparum isolates in India exhibit a progressive increase in mutation associated with sulfadoxine pyrimethamine resistance. Antimicrob. Agents Chemother. 48: 879-889.

Ahmad A., Das M.K., Dev V., Saifi M.A., Wajihullah, SharMA Y.D. 2006: Quadruple mutations in dihydrofolate reductase in Plasmodium falciparum isolates from Car Nicobar Island. Antimicrob. Agents Chemother. 50: 1546-1549.

Alam M., Bora H., Bhati R.K., Saifi M.A., Das M.K., Dev V., Kumar A., Singh S., Das A.P., Das B., Wajhhullah, SharMA Y.D. 2007: Similar trends of pyrimethamine resistance associated mutations in Plasmodium vivax and Plasmodium falciparum. Antimicrob. Agents Chemother. 51: 857-863.

AL-Harthi S.A. 2007: Chloroquine and pyrimethamine and sulfadoxine in Jazan area, Saudi Arabia using PCR and restriction digestion. J. Egypt. Soc. Parasitol. 37: 17-30.

Barnadas C., Tichit M., Bouchier C., Ratsimbasoa A., Randrianasolo L., Raherinjafy R., Jahevitra M., Picot S., MÉnARD D. 2008: Plasmodium vivax dhfr and dhps mutations in isolates from Madagascar and therapeutic response to sulphadoxine-pyrimethamine. Malar. J. 7-35.
Bosco L.K., Tahar R., Ringwald P. 1998: Molecular basis of in vivo resistance to sulfadoxin-pyrimethamin in African adult patients infected with Plasmodium falciparum malaria parasite. Antimicrob. Agents Chemother. 42: 1811-1814.

Foote S.J., Cowman A.F. 1994: The mode of action and the mechanism of resistance to antimalarial drugs. Acta Trop. 56: 157-171.

Gesase S., Gosling R.D., Hashim R., Ord R., Naidoo I., Madebe R., Mosha J. F., Joho A., Mandia V., Mrema H., Mapunda E., Savael Z., Lemnge M., Mosha F.W. Greenwood B., Roper C., Chandramohan D. 2009: High resistance of Plasmodium falciparum to sulphadoxine/pyrimethamine in northern Tanzania and the emergence of dhps resistance mutation at Codon 581. PLoS ONE. 4: 4569.

Gregon A., Plowe C.V. 2005: Mechanism of resistance of malaria parasites to antifolates. Pharmocol. Rev. 57: 117-145.

Hapi C.T., Gbotosho G.O., Folarin O.A., Akinboye D.O., Yusuf B.O., Ebong O.O., Sowunmi A., Kyle D.E., Milhous W., Wirth D.F., Oduola A.M. 2005: Polymorphisms in Plasmodium falciparum dhfr and dhps genes and age related in vivo sulfadoxine-pyrimethamine resistance in malaria-infected patients from Nigeria. Acta Trop. 95: 183-193.

Hastings M.D., Porter K.M., Maguire J.D., Susanti I., Kania W., Bangs M.J., Sibley C.H., Baird J. K. 2004: Dihydrofolate reductase mutations in Plasmodium vivax from Indonesia and therapeutic response to sulphadoxine plus pyrimethamine. J. Infect. Dis. 189: 744-750. 
Imwong M., Pukrittayakamee S., Rénia L., Letourneur F., Charlieu J.P., Leartsakulpanich U., Looareesuman S., White N.J., Snounou G. 2003: Novel point mutations in the dihydrofolate reductase gene of Plasmodium vivax: evidence for sequential selection by drug pressure. Antimicrob. Agents Chemother. 47: 1514-1521.

Jalah R.R., Sarin N., Sud N., Alam M.T., Parikh N., Das T.K., Sharma Y.D. 2005: Identification, expression, localization and serological characterization of a tryptophane rich antigen from the human malariaparasite, P. vivax. Mol. Biochem. Parasitol. 142: $158-159$.

Kaur S., Prajapati S.K., Kalyanaraman K., Mohmmed A., Joshi H., Chauhan V.S. 2006: Plasmodium vivax dihydrofolate reductase point mutations from the Indian subcontinent. Acta Trop. 97: 174-180.

Khatoon L., Baliraine F.N., Bonizzoni M., Malik S.A., YAN G. 2009: Prevalence of antimalarial drug resistance in Plasmodium vivax and P. falciparum from a malaria-endemic area of Pakistan. Am. J. Trop. Med. Hyg. 81: 525-528.

Mitra P., Vinayak S., Chandawat H., Das M.K., Singh N., Dev V., Kumar A., Ansari M.A., Sharma Y.D. 2006: Progressive rise in point mutations associated with chloroquine resistance among Plasmodium falciparum isolates from India. J. Infect. Dis. 93: 1304-1312.

Mbugi E.V., Mutayoba B.M., Malisa A.L., Balthazary S.T., Nyambo T.B., Mshinda H. 2006: Drug resistance to sulphadoxine-pyrimethamine in Plasmodium falciparum malaria in Mlimba, Tanzania. Malar. J. 5: 94.

Mujber R.A., Adeel A.A., Chance M.L., Hassan A.A. 2011: Molecular marker of antimalarial drug resistance in Lahj Governorate, Yemen: baseline data and implications. Malar. J. 10: 245.

Nzila A.M., Mberu E.K., Sulo J., Dayo H., Winstanley A., Sibley C.H., WatKins W.M. 2000: Towards an understanding of the mechanism of pyrimethamin-sulfadoxin resistance in P. falciparum genotyping of dihydrofolate reductase and dihydropteroate synthetase of Keynian parasites. Antimicrob. Agents Chemother. 44: 991-998.

Pearce R.J., Drakeley C., Chandramohan D., Moha F., Roper C. 2003: Molecular determination of point mutation haplotypes in the dihydrofolate reductase and dihydrofolate synthetase of Plasmodium falciparum in three districts of Tanzania. Antimicrob. Agents Chemother. 47: 1347-1354.

de Pecoulas P.E, Tahar P., Yi P., Thai K.H., Bosco L.K. 2004: Genetic variation of dihydrofolate reductase gene in Plasmodium vivax in Snoul, north eastern Combodia. Acta Trop. 92: 1-6.

Peterson D.S., Walliker D., Wellems T.E. 1988: Evidence that a point mutation in dihydrofolate reductase-thymidylate synthase confers resistance to pyrimethamine in falciparum malaria. Proc. Nat. Acad. Sci. USA 85: 9114-9118.
Plowe C.V., Cortese J.F., Duimde A., Nwanyanwu O.C., Watkins W.M., Winstanley P.A., Estrada Franco J.G., Mollionede R.E., Aliva J.C., Cespedes J.L. 1997: Mutation in $P$. falciparum dihydrofolate reductase and dihydropteroate synthetase and epidemiologic patterns of pyrimethamine-sulfadoxin use and resistance. J. Infect. Dis. 176: 1590-1596.

Quintero J.P., Siqueira A.M., Tobón A., Blair S., Moreno A., Arévalo-Herrera M., Lacerda M.V., Valencia S.H. 2011: Malaria-related anaemia: a Latin American perspective. Mem. Inst. Oswaldo Cruz. 106: Suppl. 1: 91-104.

Schunk M., Kuma W. P., Miranda I. B., Osman M.E., Rower S., Alano A, Loscher T., Bingle U., Mockenhjaupt F.P. 2006: High prevalence of drug resistance mutations in Plasmodium falciparum and Plasmodium vivax in southern Ethiopia. Malar. J. 5: 54.

Shretta R., Omumbo J., Rapouda B., Snow R.W., Snow R.W. 2000: Using evidence to change antimalarial drug policy in Kenya. Trop. Med. Int. Hlth. 5: 755-787.

Sirawaraporn W., Sathitkul T., Sirawaraporn R., YuthaVong Y., SAnti D.V. 1997: Antifolate-resistant mutants of Plasmodium falciparum dihydrofolate reductase. Proc. Nat. Acad. Sci. USA 94: 1124-1129.

Sridaran S., Mc Clintock S.K., Syphard L.M., Herman K.M., Barnwell J.W., Udhayakuma V. 2010: Anti-folate drug resistance in Africa: meta-analysis of reported dihydrofolate reductase (dhfr) and dihydro-pteroate synthase (dhps) mutant genotype frequencies in African Plasmodium falciparum parasite populations. Malar. J. 9: 247.

TAKесHI M. 2001: Therapeutic efficacy of sulfadoxine-pyrimethamine and susceptibility of falciparum isolates to SP and other antimalarial drugs in children. Trop. Med. Int. Hlth. 9: 364-371.

Tuitra E., Baker J., Suprianto S., Cheng Q., Anstey N.M. 2002: Therapeutic efficacies of artesunate-sulfadoxine-pyrimethamine and chloroquine-sulfadoxine-pyrimethamine in vivax malaria pilot studies: relationship to Plasmodium vivax dhfr mutations. Antimicrob. Agents. Chemother. 46: 3947-3953.

Triglia T., Menting J., Wilson C., Cowman A.F. 1997: Mutations in dihydropteroate synthase are responsible for sulfone and sulfonamide resistance in Plasmodium falciparum. Proc. Natl. Acad. Sci. USA 94: 1394-1399.

World Health Organization 2011: World Malaria Report 2011. www.who.int/malaria/publications/atoz/9789241564403/en/index.html, 278 pp.

Zakeri S., Afsharpad M., Ghasem F., Raeisi A., Safi N., Butt W., Atta H., Duadid D.N. 2010: Molecular surveillance of Plasmodium vivax dhfr and dhps mutations in isolates from Afghanistan. Malar. J. 9: 75. 